\title{
Non-Metastatic Lung Carcinoma
}

National Cancer Institute

\section{Source}

National Cancer Institute. Non-Metastatic Lung Carcinoma. NCI Thesaurus. Code

C162570.

Lung carcinoma that is confined to the site in which it initially manifested. 